\title{
Spatial patterns of Bovine Corona Virus and Bovine Respiratory Syncytial Virus in the Swedish beef cattle population
}

\author{
Francois Beaudeau*1,2,3,4, Camilla Björkmann ${ }^{4}$, Stefan Alenius ${ }^{4}$ and Jenny Frössling 5
}

\begin{abstract}
Background: Both bovine coronavirus (BCV) and bovine respiratory syncytial virus (BRSV) infections are currently wide-spread in the Swedish dairy cattle population. Surveys of antibody levels in bulk tank milk have shown very high nationwide prevalences of both BCV and BRSV, with large variations between regions. In the Swedish beef cattle population however, no investigations have yet been performed regarding the prevalence and geographical distribution of BCV and BRSV. A cross-sectional serological survey for BCV and BRSV was carried out in Swedish beef cattle to explore any geographical patterns of these infections.

Methods: Blood samples were collected from 2,763 animals located in 2,137 herds and analyzed for presence of antibodies to BCV and BRSV. Moran's / was calculated to assess spatial autocorrelation, and identification of geographical cluster was performed using spatial scan statistics.

Results: Animals detected positive to BCV or BRSV were predominately located in the central-western and some southern parts of Sweden. Moran's / indicated global spatial autocorrelation. BCV and BRSV appeared to be spatially related: two areas in southern Sweden (Skaraborg and Skåne) had a significantly higher prevalence of BCV (72.5 and $65.5 \%$ respectively); almost the same two areas were identified as being high-prevalence clusters for BRSV (69.2 and $66.8 \%$ respectively). An area in south-east Sweden (Kronoberg-Blekinge) had lower prevalences for both infections than expected (23.8 and 20.7\% for BCV and BRSV respectively). Another area in middle-west Sweden (VärmlandDalarna) had also a lower prevalence for BRSV (7.9\%). Areas with beef herd density $>10$ per $100 \mathrm{~km}^{2}$ were found to be at significantly higher risk of being part of high-prevalence clusters.
\end{abstract}

Conclusion: These results form a basis for further investigations of between-herds dynamics and risk factors for these infections in order to design effective control strategies.

\section{Background}

Bovine coronavirus (BCV) and bovine respiratory syncytial virus (BRSV) are frequently involved in the respiratory and enteric disease complexes of cattle $[1,2] . \mathrm{BCV}$ is causing winter dysentery in adults [3,4], calf diarrhoea [5] and also respiratory disease of young stock [6]. BRSV is recognized as one of the most important causes of respiratory tract disease in beef and dairy cattle, especially in young animals [7-9].

* Correspondence: francois.beaudeau@oniris-nantes.fr

1 ONIRIS, UMR 1300 Bioagression, Epidémiologie et Analyse de Risque, BP 40706, F-44307, Nantes, France

Full list of author information is available at the end of the article
Presence of antibodies to BCV [10-15] and to BRSV $[9,10,12,16,17]$ has been reported worldwide in both dairy and beef cattle.

Both BCV infection and BRSV infection are considered relatively contagious and are currently wide-spread in the Swedish dairy cattle population. Surveys of antibody levels in bulk tank milk have shown very high nationwide prevalences of both BCV [13] and BRSV [9], with large variations between regions. The highest herd-prevalences (90 to 100\%) were found in the southern parts of the country. It was suggested that a reason for the higher $\mathrm{BCV}$ prevalence in the south could be the high dairy-herd density, associated with an increased risk of spread between herds through infected animals, vectors and air- 
borne transmission [13]. In the Swedish beef cattle population however, no investigations have yet been performed regarding the prevalence and geographical distribution of BCV and BRSV.

The aim of the present study was to identify possible high risk areas for BCV and BRSV infections in the beef cattle population in Sweden, and further to explore whether a high beef herd-density was a risk factor for higher seroprevalences.

\section{Materials and methods Study design}

The cross-sectional study was conducted on blood samples collected within the Swedish Bovine Viral Diarrhoea (BVD) surveillance program. Within this program, all Swedish herds are required to be tested on a regular basis to maintain their BVD free status [18]. For beef cattle herds, depending on the number of dams present in the herd, five to ten blood samples are taken in young stock over 12 months of age per herd-year and sent to the National Veterinary Institute where they are analyzed for presence of BVDV antibodies [19]. In total, approximately 45,000 blood samples are collected annually from beef herds.

Between November 2006 and May 2007, every 12 blood sample was systematically selected for an investigation of Neospora caninum in Swedish beef cattle [20]. The same study sample was used here; it consisted of 2,763 serum samples originating from 2,137 herds, corresponding to approximately $20 \%$ of all beef herds present in the country at this time. The sample was considered to be representative of the Swedish beef cattle population, as it was issued from a procedure functionally similar to a random sampling. The number of blood samples taken per herd ranged from 1 to 8 , but most herds were represented by one or two samples ( 81 and $14 \%$, respectively).

\section{Diagnostic tests}

The samples were analysed for presence of immunoglobulin G antibodies to BCV [4] and BRSV [21] by commercially available indirect enzyme-linked immunosorbent assays (ELISA; SVANOVA Biotech, Uppsala, Sweden). The optical density (OD) at $450 \mathrm{~nm}$ was corrected by subtraction of the negative control antigen OD. Cut-off was set to a corrected OD of 0.20 , which is recommended by the manufacturer for individual samples. At this cut-off, the sensitivity is estimated to $84.6 \%$ for BCV and $94.6 \%$ for BRSV and specificity to $100 \%$ for both tests (SVANOVA manual). A sample was considered test positive if its corrected OD was $>0.20$, and test negative otherwise.

\section{Location data}

The locations of all Swedish beef herds, including the herds where the blood samples were collected, were specified by three-digit postal codes. Postal codes were retrieved from the database of the organization responsible for the BVD surveillance program, i.e. the Swedish Dairy Association (year 2007). Applicable postal codes were available for 2,757 samples from 2,131 beef herds in the study population.

\section{Spatial analyses}

For BCV and BRSV infections separately, the spatial distribution of samples and possible clustering were investigated by following the same procedure using data aggregated by postal code area (PCA).

The crude prevalence was defined as the number of positive samples over the total number of samples and was calculated for each PCA. This raw prevalence was adjusted by applying a Spatial Empirical Bayes smoothing (SEB), i.e. adjusted (i) for the potential biasing effects of variance instability due to differences in the size of the population at risk, and (ii) considering the estimates from neighboring areas [22]. Presence of global spatial autocorrelation was tested using the Moran's I test for SEB rates [23]. Its significance was calculated by Monte-Carlo simulation. All smoothing and testing for spatial associations of area aggregated data was performed using the GeoDa software version 0.9.5-i5 http://geodacenter.asu.edu/.

Identification of potential clusters of positive samples was based on location determined by PCA centroids, and using the spatial scan statistic (M. Kulldorff and Information Management Services, Inc. SatScan version 8.0, http://www.satscan.org, 2009). The method is based on either circles or ellipses centered on each PCA centroid; a Relative Risk can be estimated which compares the risk of being a case inside the circle/ellipse to the risk of being a case outside the circle/ellipse [24]. A circle/ellipse is considered a cluster if the Relative Risk is significantly higher or lower than one, when significance was tested using Monte-Carlo simulation. In this study, Poisson models applying both different cluster shapes (circular and elliptic) and sizes (maximum cluster sizes of 50, 20 and 10\% of the total population at risk) were built to identify both high-risk and low-risk clusters. No overlapping of the circles/ellipses was allowed.

$\mathrm{BCV}$ and BRSV are contagious, and test positive animals are expected to be grouped in herds. As the likelihood of detecting at least one test positive animal increases with the number of individual samples collected per herd, identification of clusters and their spatial location might be biased if the herds from which two or 
more blood samples (19\% of the studied herds) were collected are not evenly geographically-distributed. To investigate this potential bias in relation to the sampling strategy, possible clustering of herds with more than one sampled animal was explored in a preliminary step by using Moran's $I$. This test indicated that these herds were proportionally distributed over Sweden (data not shown).

To test whether or not a high beef herd-density was a risk factor for significantly higher seroprevalences of $\mathrm{BCV}$ and BRSV than expected, univariate logistic regression analysis was performed at PCA level, where the binary outcome was "PCA with a significantly higher number of positive-tested samples $v s$. without" and the putative explanatory variable was the PCA herd-density (in herds $/ 100 \mathrm{~km}^{2}$ ) in 3 classes $[<5 ; 5-10 ;>10]$.

Data management, statistics and creation of map shape-files were performed using SAS 9.2 (SAS Institute, Inc., Cary, NC, USA) and ArcGIS 9.1 (ESRI Inc., Redlands, CA, USA).

\section{Results}

The overall prevalence of animals testing positive to BCV and BRSV was 43.1 (95\% CI: 41.3-45.0) and 39.2\% (95\% CI: 37.3-41.0) respectively. There was a statistically significant $\left(\mathrm{P}<0.01, \mathrm{X}^{2}\right.$-test) relationship between $\mathrm{BCV}$ and BRSV serological status, i.e. BCV-positive animals were more likely to be BRSV-positive and vice versa. Animals testing positive to $\mathrm{BCV}$ were predominately located in the central-western and southern Sweden, as well as in some northern areas (Figure 1a). Animals testing positive to BRSV were predominately found in the same centralwestern and southern parts of the country (Figure 2a). When the prevalences were adjusted by SEB, these tendencies became even clearer (Figures $1 b$ and $2 b$ ) and the northern areas were no longer considered having high prevalences for BCV.

The findings were confirmed by significant Moran's $I$ tests for both infections $(0.15, \mathrm{P}=0.0001$ for $\mathrm{BCV} ; 0.16, \mathrm{P}$ $=0.001$ for BRSV), suggesting that the test positive animals were not randomly distributed throughout the country.

Using the spatial scan statistic with elliptic clusters and a maximum cluster size of $10 \%$ of the population at risk identified two areas with higher prevalence of BCV than expected: Skaraborg (central-south part of Sweden) and Skåne (extreme south), as well as one area with lower prevalence than expected: Kronoberg-Blekinge (southeast of Sweden; Figure 3a). Almost the same high prevalence areas (Skaraborg and Skåne) were identified as being clusters for BRSV. Two areas with low prevalence of BRSV were also detected: Kronoberg-Blekinge and
Värmland-Dalarna (middle-west) (Figure 3b). The characteristics of the identified clusters are displayed in Table 1.

The beef-herd density per PCA is presented in Figure 4. Among the 34 PCAs included in the clusters of high BCV prevalence, 20 had a beef herd-density $>10$ herds/100 $\mathrm{km} 2$. This proportion was 14 out of 22 for BRSV. For $\mathrm{BCV}$, the risk for a PCA to be part of a cluster of high prevalence was 5.3 times (95\% CI: 2.5-11.1) higher if its beef herd-density was $>10$ herds $/ 100 \mathrm{~km} 2$ than if it was $<10$ herds/100 km2; this risk was 6.1 times (95\% CI: 2.415.1) higher for BRSV.

\section{Discussion}

This study showed, from visual inspection and descriptive analyses, that both BCV and BRSV infections are very frequent in Swedish beef cattle, especially in some central-western and southern parts of the country. The results are in accordance with what has been reported for dairy cattle where prevalences of BCV- and BRSVinfected dairy herds have been shown to increase with a gradient southward in the country $[9,13,25]$. A recent study has also shown substantial production effects (e.g. reduced milk yield) associated with BRSV infection in Swedish dairy herds [26].

There was a strong relationship at animal level between being tested positive to BCV and BRSV, and exploratory spatial analyses also indicated two areas with particularly high prevalences for both BCV and BRSV, i.e. Skaraborg and Skåne. The association between BCV and BRSV is biologically plausible because both viruses are relatively contagious and have transmission routes that are to some extent similar. A concomitant BRSV and BCV infection burden and spread in calves has also been demonstrated [10,27].

For both infections, the prevalence of animals testing positive was approximately $40 \%$. However these apparent prevalences at individual level are probably underestimated. Because a few individuals were sampled from each herd (one or two in $95 \%$ of herds in the study sample) the herd sensitivity was here low. As a consequence, it can be assumed that a proportion of infected herds and of infected individuals within these herds could have been missed (as both viruses are highly contagious within herd), thus decreasing the apparent individual-level prevalences. This study was not predominately designed to estimate the seroprevalences of BCV and BRSV infections in Sweden, but to explore their spatial distribution.

Both high prevalence areas have a relatively high density of beef herds (13 and 22 per $100 \mathrm{~km}^{2}$ in Skaraborg and Skåne, respectively). In addition, the area with the 

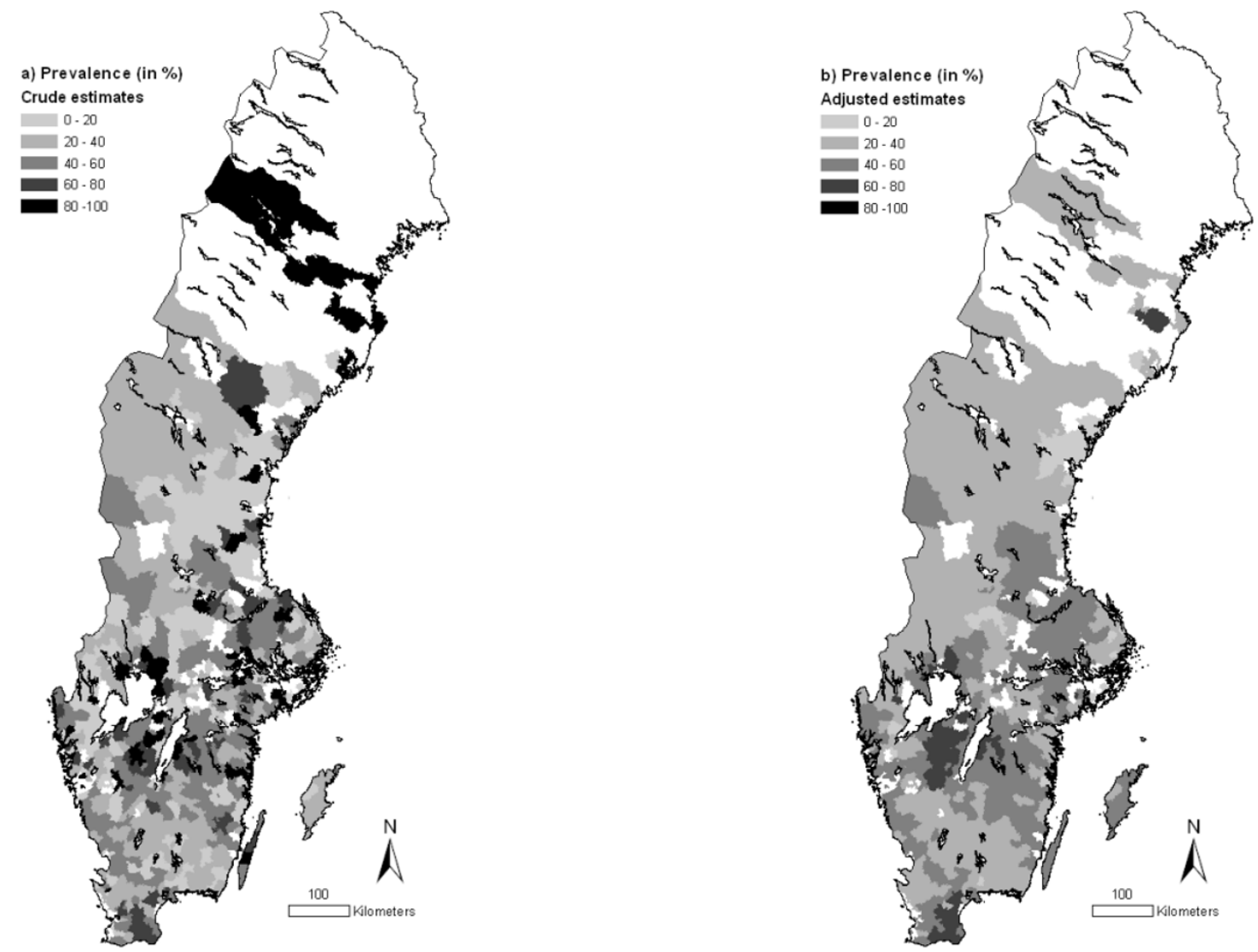

Figure 1 Prevalence of BCV in Swedish beef cattle by three-digit postal code area (2007). The estimates presented are (a) crude or (b) adjusted by empirical Bayes smoothing applying a spatial weight matrix. Information was missing for the white areas. ${ }^{\circledR}$ Lantmäteriverket Gävle 2010 . Permission number I 2010/0055.

lowest prevalence for BRSV has a very low beef herd density $\left(2\right.$ per $\left.100 \mathrm{~km}^{2}\right)$. This suggests a positive association between herd-density and risk of infection. Statistical analysis confirmed that areas with herd-density $>10$ per $100 \mathrm{~km}^{2}$ had significantly higher risk of being part of high-prevalence clusters. A probable explanation is that a short distance between herds increases the risk of spread of the viruses. In such situations, there is a higher likelihood of direct and indirect contact (through e.g. animals, vehicles or visitors) between herds and animals. However, some PCAs in the low-prevalence cluster Kronoberg-Blekinge also had a beef herd-density $>10$ per $100 \mathrm{~km}^{2}$, suggesting that there are other factors with uneven geographic distribution that have an impact on the $\mathrm{BCV}$ and BRSV prevalences. Live animal trade, in particular, is considered very important for the spread of infectious diseases and a recent study show that the number of movements and trade patterns in different parts of Sweden vary considerably [28].

Large herd size has also been identified as risk factor for BCV and BRSV infections in dairy cattle $[13,27]$ and for respiratory disease outbreaks in beef cattle [29]: on increasing the herd size from 20 to 50 animals, the risk for disease outbreak increased 2.1-fold. The size of Swedish beef herds differs between regions and there is a tendency for smaller herd sizes in the regions covering the identified low prevalence areas compared to the high prevalence areas (10 beef adults per herd in KronobergBlekinge versus 16 in Skåne, based on information from the database of the Swedish Board of Agriculture). Also regional differences in biosecurity and management routines in relation to farming styles can be assumed. Based on a study on Swedish dairy farms, it has been suggested that organic herds may have a reduced risk of $\mathrm{BCV}$ and 

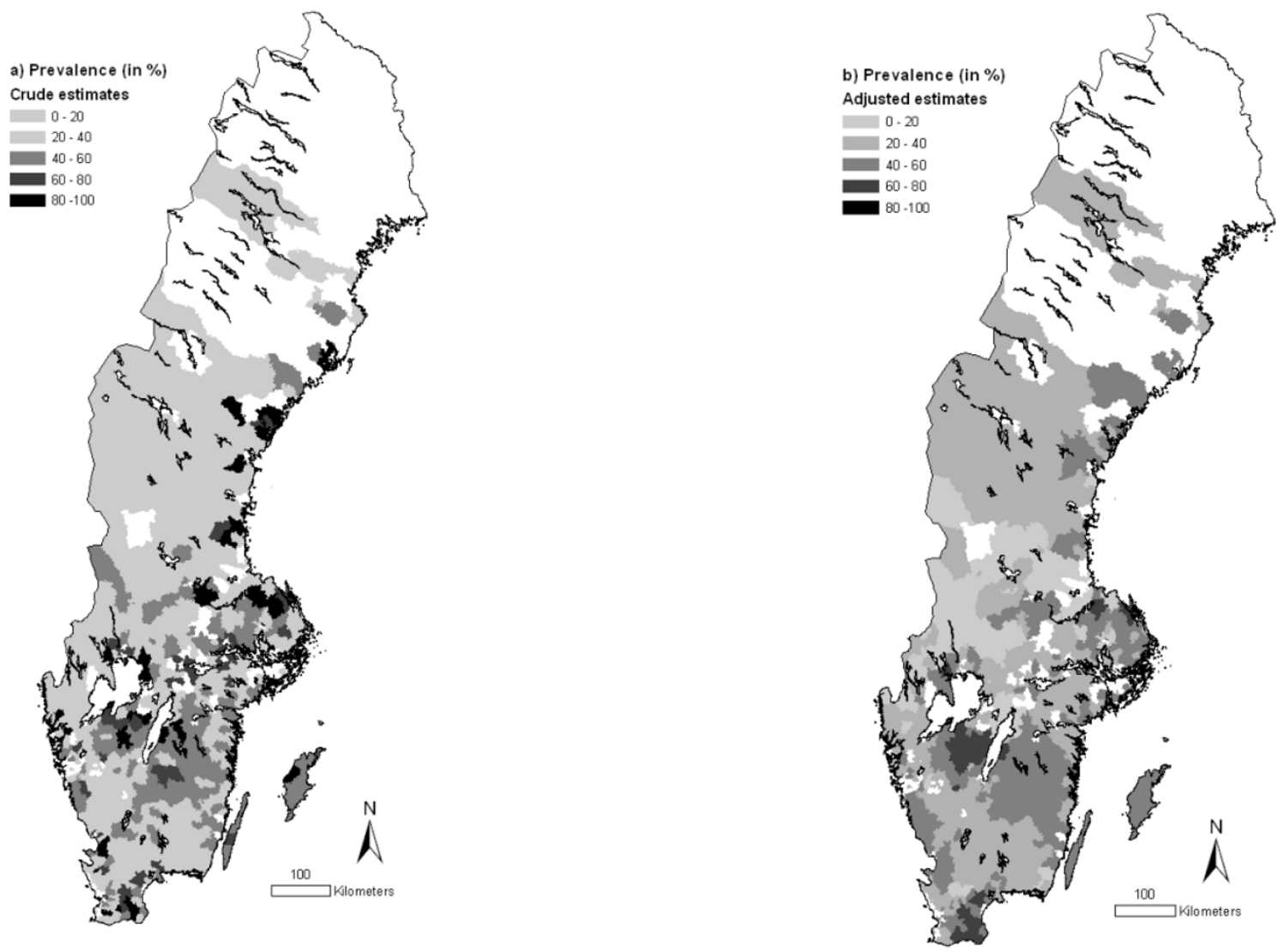

Figure 2 Prevalence of BRSV in Swedish beef cattle by three-digit postal code area (2007). The estimates are (a) crude or (b) adjusted by empirical Bayes smoothing applying a spatial weight matrix. Information was missing for the white areas. ${ }^{\circledR}$ Lantmäteriverket Gävle 2010. Permission number I 2010/0055

Table 1: Characteristics of the three areas in Sweden with significantly higher or lower BCV and BRSV prevalences obtained by a spatial scan statistic (Kulldorff, 1997).

\begin{tabular}{|c|c|c|c|c|c|c|c|c|}
\hline \multirow[t]{2}{*}{ Clusters } & \multicolumn{4}{|l|}{ BCV } & \multicolumn{4}{|l|}{ BRSV } \\
\hline & Area $\left(\mathbf{k m}^{2}\right)$ & Samples (n) & Prevalence (\%) & $\mathbf{R R}^{1}$ & Area $\left(\mathbf{k m}^{2}\right)$ & Samples (n) & Prevalence (\%) & $\mathbf{R R}^{1}$ \\
\hline Skaraborg & 7,585 & 207 & 72.5 & $1.77^{* *}$ & 4,734 & 156 & 69.2 & $1.85^{* *}$ \\
\hline Skåne & 3,748 & 254 & 65.5 & $1.51^{* *}$ & 2,852 & 223 & 66.8 & $1.82^{* *}$ \\
\hline Kronoberg-Blekinge & 10,145 & 247 & 23.8 & $0.53^{* *}$ & 15,397 & 401 & 20.7 & $0.51^{*}$ \\
\hline Värmland-Dalarna & - & & - & - & 31,435 & 89 & 7.9 & $0.20^{* *}$ \\
\hline
\end{tabular}



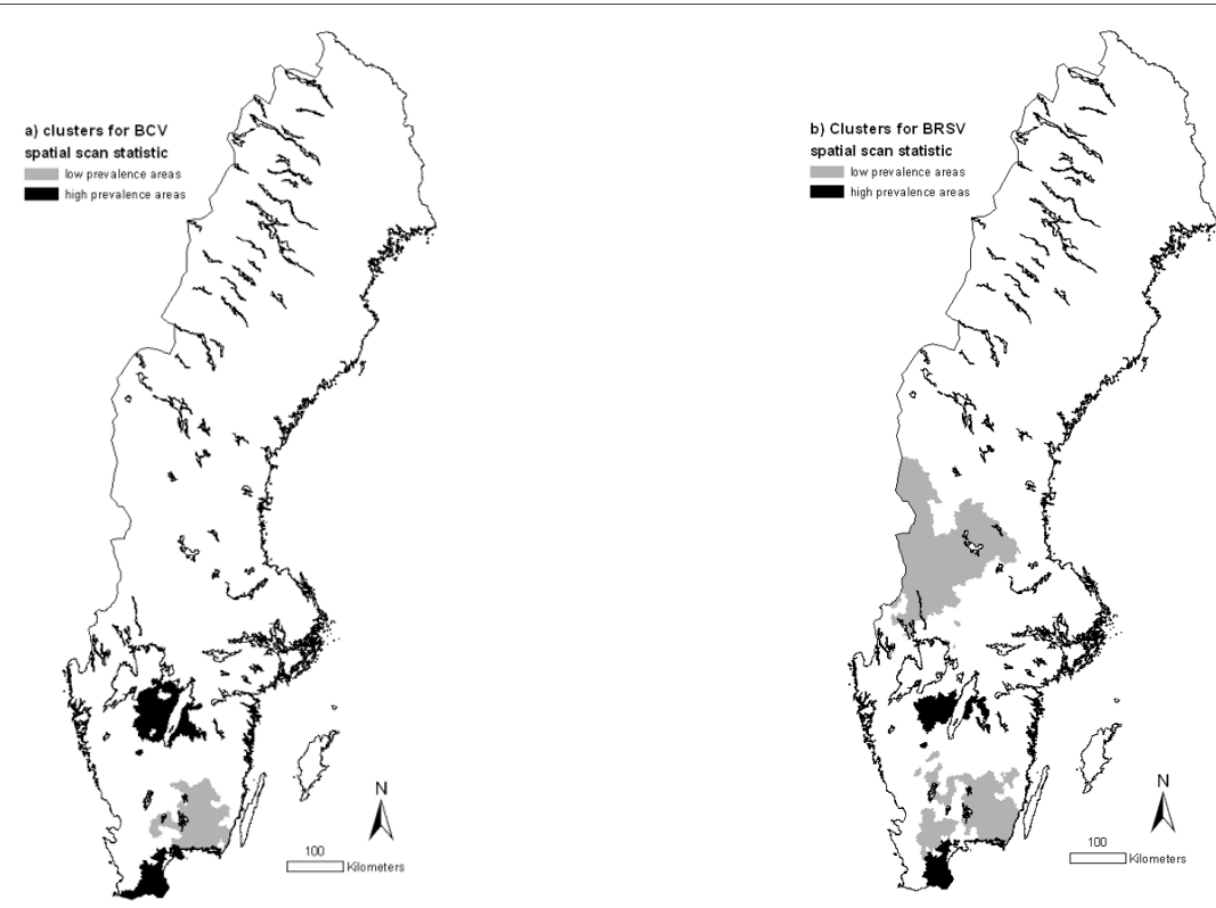

Figure 3 Areas with high or low prevalences of (a) BCV and (b) BRSV, obtained by a spatial scan statistic (Kulldorff, 1997), using the centroids of the three-digit postal code areas as coordinates ( $\mathbf{p}<\mathbf{0 . 0 1}$ ). ${ }^{\odot}$ Lantmäteriverket Gävle 2010 Permission number I 2010/0055.

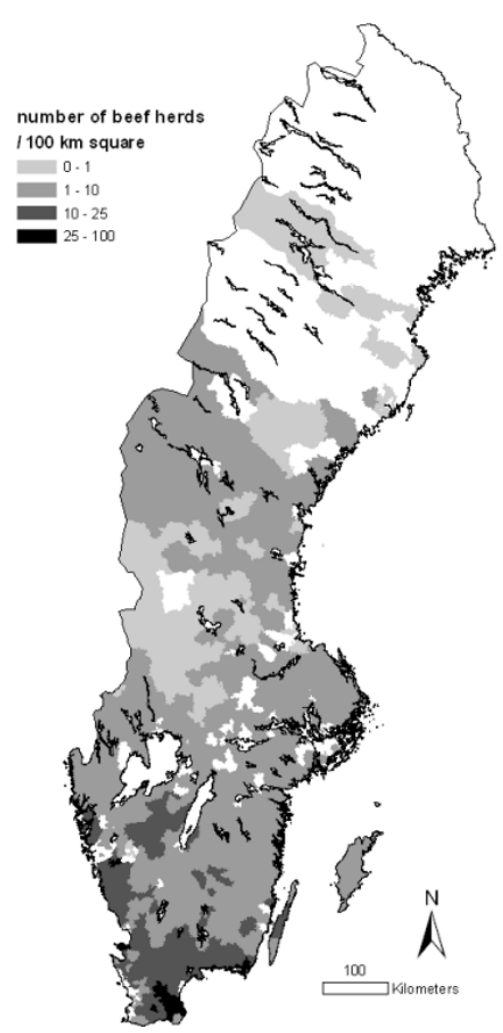

Figure 4 The population of Swedish beef herds presented as density by three-digit postal code area (2007). ${ }^{\odot}$ Lantmäteriverket Gävle 2010. Permission number I 2010/0055.
BRSV infections, when compared to conventional herds [30]. To quantify the relative impact of potential risk factors for a herd to be detected as BCV or BRSV-infected (e.g. trade intensity, density of dairy herds, herd size, biosecurity measures, type and number of visitors), studies could be conducted by comparing herd characteristics and management practices in the low and high-risk areas identified. The results of such studies would enlighten the choice of relevant strategies to control BCV and BRSV infections not only in Sweden, but also in other areas where herds have to some extent similar characteristics.

\section{Conclusions}

The present study shows that BCV and BRSV infections in beef cattle are not equally distributed throughout Sweden and higher-prevalence areas are located in the same southern parts of the country. These results form a basis for further investigations of between-herds dynamics and risk factors for these infections aiming to design effective control strategies. They are also of interest and could be utilized for risk-based approaches in the surveillance of absent or emerging infectious diseases in cattle.

\section{Competing interests}

The authors declare that they have no competing interests.

\section{Authors' contributions}

FB participated in the design of the study, performed the statistical analyses and drafted the manuscript. CB participated in the design of the study and helped to draft the manuscript. SA helped to draft the manuscript. JF participated in the design of the study, contributed to the statistical analysis and helped to draft the manuscript. All authors read and approved the final manuscript. 


\section{Acknowledgements}

We thank Maj Hjort for valuable technical assistance and the Swedish Dairy Association for providing blood samples and information from the database.

\section{Author Details}

1ONIRIS, UMR 1300 Bioagression, Epidémiologie et Analyse de Risque, BP 40706, F-44307, Nantes, France, 2INRA, UMR 1300 Bioagression, Epidémiologie et Analyse de Risque, BP 40706, F-44307, Nantes, France, ${ }^{3}$ Université Nantes Angers Le Mans, Nantes, France, ${ }^{4}$ Department of Clinical Sciences, Swedish University of Agricultural Sciences, PO Box 7054, SE-750 07, Uppsala, Sweden and ${ }^{5}$ Department of Disease Control and Epidemiology, National Veterinary Institute (SVA), SE-751 89 Uppsala, Sweden

Received: 29 March 2010 Accepted: 21 May 2010

Published: 21 May 2010

\section{References}

1. Clark MA: Bovine coronavirus. Brit Vet J 1993, 149:51-70.

2. Valarcher JF, Taylor G: Bovine respiratory syncytial virus infection. Vet Res 2007, 38:153-180.

3. Saif $\mathrm{L}$ : A review of evidence implicating bovine coronavirus in the etiology of winter dysentery in cows: an enigma resolved? Cornell Vet 1990, 80:303-311.

4. Alenius S, Niskanen R, Juntti N, Larsson B: Bovine coronavirus as the causative agent of winter dysentery: serological evidence. Acta Vet Scand 1991, 32:163-170

5. Stair EL, Rhodes MB, White RG, Mebus CA: Neonatal calf diarrhoea: purification and electron microscopy of a coronavirus-like agent. Am J Vet Res 1972, 33:1 147-1156.

6. McNulty MS, Bryson DG, Allan GM, Logan EF: Coronavirus in the respiratory tract. Vet Microbiol 1984, 9:425-434.

7. Stott EJ, Thomas LH, Collins AP, Crouch S, Jebbett J, Smith GS, Luther PD, Caswell R: A survey of virus infections of the respiratory tract of cattle and their association with disease. J Hyg 1980, 85:257-270.

8. Verhoeff J, Ban J Van der, Van Nieuwstadt AP: Bovine respiratory syncytial virus infections in young dairy cattle: clinical and hematological findings. Vet Rec 1984, 114:9-12.

9. Elvander M: Severe respiratory disease in dairy cows caused by infection with bovine respiratory syncytial virus. Vet Rec 1996, 3:101-105.

10. Ganaba R, Bélanger D, Dea S, Bigras-Poulin M: A seroepidemiological study of the importance in cow-calf pairs of respiratory and enteric viruses in beef operations from northwestern Quebec. Can $J$ Vet Res 1995, 59:26-33.

11. Motha MXJ, Hansen MF: Prevalence of IBR, PI 3, BRS and BCV infections in the dairy cattle population of New Zealand. New Zeal Vet J 1998, 46:239-240.

12. Paton DJ, Christiansen KH, Alenius S, Cranwell MP, Pritchard GC, Drew TW: Prevalence of antibodies to bovine virus diarrhoea virus and other viruses in bulk tank milk in England and Wales. Vet Rec 1998, 142:385-391.

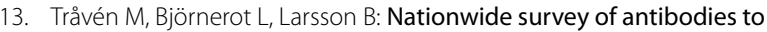
bovine coronavirus in bulk milk from Swedish dairy herds. Vet Rec 1999, 144:527-529.

14. Uhde FL, Kaufmann T, Sager H, Albini S, Zanoni R, Schelling E, Meylan M: Prevalence of four enteropathogens in the faeces of young diarrhoeic dairy calves in Switzerland. Vet Rec 2008, 163:362-366.

15. Yildirim Y, Dagalp SB, Tan MT, Kalaycioglu AT: Seroprevalence of the rotavirus and corona virus infections in cattle. J Anim Vet Adv 2008, 7:1320-1323.

16. Solís-Calderón JJ, Segura-Correa JC, Aguilar-Romero F, Segura-Correa VM: Detection of antibodies and risk factors for infection with bovine respiratory syncytial virus and parainfluenza virus-3 in beef cattle of Yucatan, Mexico. Prev Vet Med 2007, 1-2:102-110.

17. Yeslbag K, Ylmaz Z, Gungor B: Prevalence of antibodies to bovine respiratory viruses in cattle infected with bovine immunodeficiency virus. Vet Rec 2008, 162:660-661

18. Anonymous: Surveillance and control programmes Sweden 2006 Statens Veterinärmedicinska Anstalt. [http://www.sva.se/upload/pdf/ Tiänster\%20och\%20produkter/Trycksaker/Surveillance and control programmes Sweden 2006 webb.pdf]. accessed July 23, 2008
19. Alenius S, Lindberg A, Larsson B: A national approach to the control of bovine viral diarrhoea virus. Proc 3rd ESW symposium on pestivirus infections, 19-20 Sept 1996, Lelystadt, The Netherlands 1996:162-169.

20. Loobuyck M, Frössling J, Lindberg A, Björkman C: Seroprevalence and spatial distribution of Neospora caninum in a population of beef cattle. Prev Vet Med 2009, 92:116-122.

21. Elvander M, Edwards S, Näslund K, Linde N: Evaluation and application of an indirect ELISA for the detection of antibodies to bovine respiratory syncytial virus in milk, bulk milk, and serum. J Vet Diagn Invest 1995, 7:177-182

22. Bailey TC, Gatrell AC: Further methods for area data. In Interactive Spatial Analysis Longman Group Limited, Burnt Mill, Harlow, Essex; 1995:298-328.

23. Assuncao RM, Reis EA: A new proposal to adjust Moran'/ for population density. Stat Med 1999, 18:2147-2162.

24. Kulldorff M: A spatial scan statistic. Commun Stat - Theor M 1997 26:1481-1496

25. Ohlson A, Heuer C, Lockhart C, Tråvén M, Emanuelson U, Alenius S: Risk factors for seropositivity to bovine coronavirus and bovine respiratory syncytial virus indairy herds. Vet Rec in press.

26. Beaudeau F, Ohlson A, Emanuelson U: Associations between Bovine Coronavirus and Bovine Respiratory Syncytial Virus infections and animal performance in Swedish dairy herds. J Dairy Sci 2010, 93:1523-1533

27. Hägglund S, Svensson C, Emanuelson U, Valarcher JF, Alenius S: Dynamics of virus infections involved in the bovine respiratory disease complex in Swedish dairy herds. Vet J 2006, 172:320-328.

28. Nöremark M, Håkansson N, Lindström T, Wennergren U, Lewerin SS: Spatial and temporal investigations of reported movements, births and deaths of cattle and pigs in Sweden. Acta Vet Scand 2009, 51:37-44.

29. Norström M, Skjerve E, Jarp J: Risk factors for epidemic respiratory disease in Norwegian cattle herds. Prev Vet Med 2000, 44:87-96.

30. Bidokhti MRM, Tråvén M, Fall N, Emanuelson U, Alenius S: Reduced likelihood of bovine coronavirus and bovine respiratory syncytial virus infection on organic compared to conventional farms. Vet J 2009, 182:436-440.

doi: 10.1186/1751-0147-52-33

Cite this article as: Beaudeau et al., Spatial patterns of Bovine Corona Virus and Bovine Respiratory Syncytial Virus in the Swedish beef cattle population Acta Veterinaria Scandinavica 2010, 52:33

\section{Submit your next manuscript to BioMed Centra and take full advantage of:}

- Convenient online submission

- Thorough peer review

- No space constraints or color figure charges

- Immediate publication on acceptance

- Inclusion in PubMed, CAS, Scopus and Google Scholar

- Research which is freely available for redistribution 